\title{
Intronic Mutation
}

National Cancer Institute

\section{Source}

National Cancer Institute. Intronic Mutation. NCI Thesaurus. Code C63429.

Any mutation within an intron, including the sequences that comprise the intron boundary. 